\title{
Provincial differences in levels, trends, and determinants of child- hood immunization in Pakistan
}

Adrienne Kols, ${ }^{1}$ Zulfikar Gorar, ${ }^{2}$ Muhammad Sharjeel, ${ }^{3}$ Farid Midhet, ${ }^{4}$ Rashid Nazir, ${ }^{4}$ Dileep Kumar ${ }^{5}$ and Aslam Fareed ${ }^{4}$


Pakistan. ${ }^{3}$ Marie Stopes Society, Karachi, Pakistan; Pathfinder International, Karachi, Pakistan (current). ${ }^{4}$ Jhpiego/Pakistan, Karachi, Pakistan. ${ }^{5}$ JSI Research \& Training Institute, Inc., Karachi, Pakistan; USAID/Pakistan, Karachi, Pakistan (current).

\begin{abstract}
Background: Efforts to improve immunization rates are urgently needed in Pakistan but national statistics mask important local differences in immunization levels and determinants.

Aim: In this study we aimed to determine how similar or different are recent trends and levels of immunization coverage in Pakistan's 4 main provinces [Punjab, Sindh, Khyber Pakhtunkhwa (KPK) and Balochistan], and what factors are associated with complete childhood immunization in each province.

Method: We analysed data from the 2006-07 and 2012-13 Pakistan Demographic and Health Surveys. Trends in immunization coverage among children aged 12-23 months were calculated for each province. Bivariate and multivariate analyses were conducted to identify factors associated with complete immunization.

Results: The proportion of children completely immunized had risen significantly in Punjab but had fallen significantly in Balochistan. Complete coverage ranged from 16.4\% in Balochistan to 65.8\% in Punjab (2012-13). Tetanus toxoid injection during pregnancy was a significant predictor of complete immunization everywhere. Other predictors in specific provinces were: urban residence in Balochistan, wealth in Sindh and KPK, mother's education in Punjab and KPK, and distance to the facility in Punjab.

Conclusions: Although some strategies to increase immunization coverage are relevant nationwide, programme managers need to seek solutions specific to provincial trends and predictors. This analysis demonstrates that viewing childhood immunization in Pakistan through a provincial lens can help achieve a deeper understanding of the challenges and potential strategies to boost coverage.
\end{abstract}

Keywords: immunization coverage, immunization determinants, vaccination, Pakistan, provinces

Citation: Kols A; Gorar Z; Sharjeel M; Midhet F; Nazir R; Kumar D; et al. Provincial differences in levels, trends, and determinants of childhood immunization in Pakistan. East Mediterr Health J. 2018;24(4):333-344. https://doi.org/10.26719/2018.24.4.333

Received: 22/06/16; accepted: 29/03/17

Copyright (C) World Health Organization (WHO) 2018. Some rights reserved. This work is available under the CC BY-NC-SA 3.o IGO license (https:// creativecommons.org/licenses/by-nc-sa/3.o/igo).

\section{Introduction}

Many children in Pakistan remain unvaccinated every year, contributing to frequent outbreaks of vaccine-preventable diseases such as measles (1) and hindering the eradication of polio (2). Low immunization rates in Pakistan have been attributed to a wide variety of factors. On the supply side, reports have pointed to weaknesses at every level of the vaccination delivery system, including a lack of planning, supervision, and monitoring, weaknesses in the logistics system, limited numbers of vaccination points, staff shortages and lack of motivation, and political interference in the Expanded Programme on Immunization (EPI) (1,3-6). On the demand side, research suggests that parents may not get children vaccinated because of a lack of awareness, misconceptions fed by negative propaganda and religious beliefs, and difficulties accessing vaccination services (6-10). Armed conflict, natural disasters and consequent internal displacement of large populations have sowed distrust and made it even more difficult to reach children with basic vaccinations $(6,11)$. In the case of polio, violence against vaccinators and local government bans have also limited immunization coverage (12).

The situation is further complicated by large disparities in the levels and determinants of vaccination within Pakistan. Region - but not urban-rural residence - proved to be a significant factor predicting incomplete immunization in a multivariable analysis of data from the 2006-07 Pakistan Demographic and Health Survey (PDHS) (13). A mixed methods study carried out in 4 districts of Pakistan located in different provinces found that measles immunization coverage varied from $50 \%$ to $86 \%$ between districts and that the factors associated with measles vaccination differed between, and even within, districts (14). These disparities are not surprising: Pakistan's provinces differ widely on a host of demographic, economic, social, cultural and political characteristics that may affect the delivery and uptake of immunization services (15). The dissolution of the Federal Ministry of Health and the devolution of all health care service delivery, including EPI, to provincial governments in 2011 may have exacerbated regional 
differences in immunization coverage, given the uneven implementation and lack of capacity at the provincial and district levels $(15,16)$.

Given the disparities in the levels and determinants of childhood immunization within Pakistan, provincial EPI managers must understand local realities if they are to increase vaccination rates. This analysis takes a first step in this direction by analysing immunization data from the PDHS for 2006-07 and 2012-13 at the provincial level. We seek to answer 2 questions: first, how similar or different are recent trends and levels of immunization coverage in Pakistan's 4 main provinces, and second, what factors are associated with complete childhood immunization in each province? We briefly consider the implications of these findings for provincial policymakers and programme managers.

\section{Study design and sampling}

We conducted a secondary analysis of data from the 2 most recent rounds of the PDHS, which were conducted in 2006-07 and 2012-13, to assess immunization levels and trends. The National Institute of Population Studies and MEASURE DHS programmes were responsible for designing these cross-sectional studies, collecting the data and conducting the primary analysis. These household surveys were designed to be nationally representative and also to provide reliable estimates of key indicators at the provincial level. Full descriptions of the sampling and data collection methods employed by the surveys are available elsewhere (17,18). In brief, a 2-stage, stratified, random sample design was used to identify sample points (census enumeration blocks in urban areas and villages in rural areas), with probability proportional to size, and then to select households. Urban areas and smaller regions, including the province of Balochistan, were oversampled, and PDHS researchers adjusted proportions by applying sampling weights during the primary analysis.

Interviews were conducted with 13558 ever-married women aged 15-49 years from 13944 selected households in 2012-13 and with 10023 women from 9712 households selected for the women's questionnaire in 2006-07. However, this analysis is restricted to women who had a living child aged 12-23 months at the time of the interview; these children are from the youngest age group who are supposed to be fully immunized, and provide the best indicator of current immunization coverage. There were 1707 women with children aged 12-23 months in the 2012-13 PDHS sample, 593 in Punjab, 417 in Sindh, 423 in Khyber Pakhtunkhwa (KPK) (formerly North-West Frontier Province) and 274 in Balochistan. The 2006-07 PDHS sample included 1528 mothers with children aged 12-23 months: 621 in Punjab, 434 in Sindh, 312 in KPK and 161 in Balochistan.

\section{Data collection}

Female interviewers (mostly university graduates) received 3 weeks of training and were closely supervised in the field to assure the quality of the data. At each home visited, they completed a household questionnaire and then conducted individual interviews with ever-married women and men aged 15-49 years. Most of the data in this analysis come from the women's questionnaire, including information on childhood vaccinations and utilization of maternal and child health services. To document which vaccinations a child had received, interviewers asked to see his or her immunization card. If the card was not available, they asked the mother what vaccines had been given to the child. Mothers were able to show immunization cards for $36.0 \%$ of children aged $12-$ 23 months in the 2012-13 PDHS (19), up from $23.7 \%$ in the 2006-07 PDHS (18). Information on wealth comes from the household questionnaire; the DHS programme uses information on housing characteristics and ownership of durable goods to generate a wealth index and assign households to wealth quintiles.

\section{Indicators and data analysis}

We used complete immunization as the primary measure of a child's immunization status. Following World Health Organization guidelines, complete immunization is defined as receiving 1 dose of vaccine against tuberculosis (BCG); 3 doses of vaccine against diphtheria, pertussis and tetanus (DPT); 3 doses of oral polio vaccine (OPV), excluding polio vaccine given at birth; and 1 dose of measles vaccine. The DPT immunization includes newer tetravalent and pentavalent vaccines that also protect against hepatitis and Haemophilus influenzae as well as trivalent vaccines. According to the routine immunization schedule in Pakistan, children should receive all 8 doses during the first year of life: BCG at birth; DPT and OPV at 6, 10 and 14 weeks; and measles vaccine at 9 months. We also examined coverage for each individual vaccine, dropout rates for DPT (DPT1-DPT3) and polio ( $\left.\mathrm{OPV}_{1}-\mathrm{OPV}_{3}\right)$, the proportion of children who received no vaccinations and the proportion of children with an immunization card.

To analyse the determinants of immunization in 2012-13, we selected 15 independent variables based on a literature review (20) and analyses of the 2006-07 PDHS $(13,19)$. These variables included: children's characteristics (sex and birth order), mothers' characteristics (age and education), household characteristics (wealth quintile and urban-rural residence), utilization of health services during the woman's most recent pregnancy (antenatal care visits, tetanus toxoid injections and delivery at a health facility), problems accessing health care (getting permission, getting money, distance to facility, not wanting to go alone and transportation), and women's participation in household decisions.

All analyses were conducted independently for Pakistan's 4 major provinces (Punjab, Sindh, KPK, and Balochistan), which account for more than $95 \%$ of the country's total population; 2 smaller regions (ICT Islamabad and Gilgit Baltistan) were excluded. Reported n's are actual sample frequencies, but all other reported numbers are weighted and have accounted for clustering in the data. To account for clustering, we used the svyset command in STATA 11 to declare the cluster and weight variables and then the svy prefix command for all analyses to fit statistical models for complex survey data. Trends in 
immunization were analysed by comparing proportions from the 2 most recent PDHS surveys and running chi-squared tests. To analyse the association between independent variables and complete immunization in the 2012-13 survey, we ran bivariate comparisons with selected binary and categorical variables using chisquared tests. We also examined variables such as birth order and mother's age as interval data in trend analyses. The results were similar and are not reported here.

All variables that were significant in the bivariate analysis were entered into multiple logistic regression models by region. We used stepwise regression to perform a backward-selection estimation to remove factors based on a significance level of o.1. Any factors remaining in any of the regional models were then entered into the final multivariable model and re-run without stepwise regression. Adjusted odds ratios (ORs) and $95 \%$ confidence intervals (CIs) were calculated to show the magnitude of associations.

The 2012-13 data contain 14 sets of twins and 1 set of triplets; 1 child from each set was chosen at random and the other(s) dropped due to the near perfect correlation of vaccinations within each set.

\section{Ethical considerations}

Data files for the 2 PDHS surveys were requested and received from the DHS programme (www.dhsprogram. com). The survey protocols were approved by institutional review boards in Pakistan and at ICF International; no additional ethical approvals were required for re-analysis of the datasets.

\section{Results}

\section{Levels and trends in immunization}

Levels and recent trends in complete immunization coverage vary between provinces (Figure 1). From 2006-07 to 2012-13, the proportion of children aged 12-23 months who were completely immunized increased in Punjab by 13.1 percentage points and in KPK by 6.7 percentage points; these were also the provinces with the highest immunization coverage in 2005-06. In contrast, the proportion of fully immunized children fell in Sindh by $8.1 \%$ and in Balochistan by 18.5 percentage points. In 2012-13, immunization coverage ranged from a low of 16.4 percentage points in Balochistan to a high of 65.8 percentage points in Punjab.

Punjab showed significant improvements from 2006-07 to 2012-13 on all immunization indicators except measles vaccination (Table 1). Most indicators improved in KPK, but only an increase in DPT3 coverage and decrease in the DPT dropout rate were significant. The reverse was true in Sindh: most indicators worsened over time, but only a decrease in $\mathrm{DPT} 3$ coverage and increase in the DPT dropout rate were significant. All indicators in Balochistan worsened over time, and the change was significant for DPT3 coverage, complete immunization and the OPV dropout rate.

\section{Determinants of immunization}

The bivariate analysis in Table 2 examines whether children's mothers', or household characteristics were associated with complete immunization in each province in 2012-13. Coverage declined significantly with birth order

\footnotetext{
Figure 1 Proportion of children aged 12-23 months who were completely immunized in Pakistan's four main provinces (Pakistan Demographic and Health Survey) (KPK = Khyber Pakhtunkhwa)
}

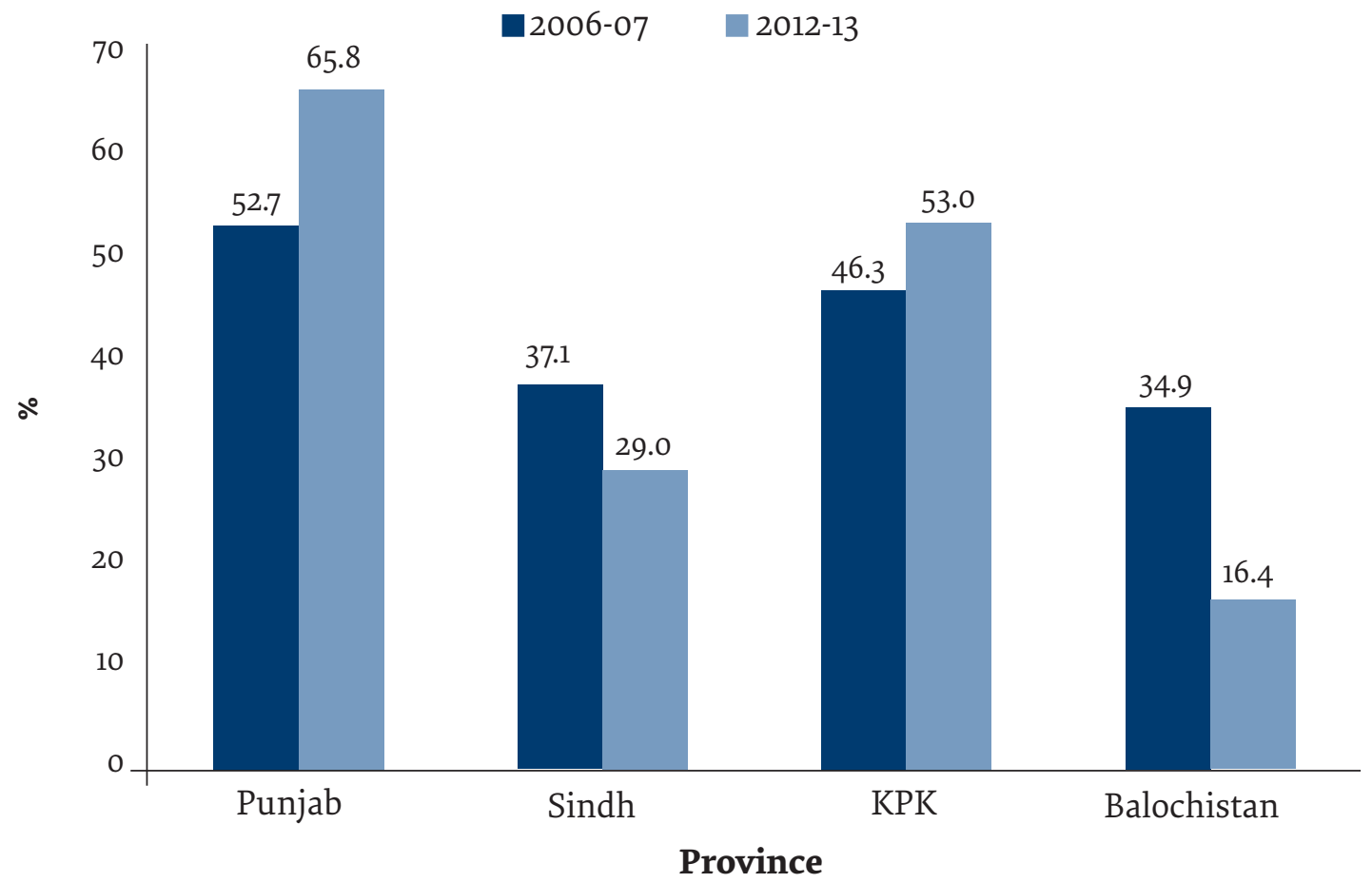






in Sindh and Punjab, but the drop-off began at birth order 4-6 in Sindh, compared with birth order $7+$ in Punjab. Immunization coverage increased significantly with mother's education in every province except Balochistan, and with household wealth in all 4 provinces; however, only the poorest quintile was at a disadvantage in Punjab. Coverage was significantly higher in urban than rural areas in every province except KPK. Disparities in immunization coverage by education, wealth, and urban/rural residence were greater in Sindh than in other provinces.

Immunization levels varied with mother's utilization of health services during her last pregnancy. In all 4 provinces, immunization coverage was significantly higher when mothers had received 2 tetanus toxoid (TT) injections (the number needed to protect neonates) and had delivered in a facility. Coverage was also positively associated with making at least 4 antenatal clinic visits in Punjab, Sindh and KPK. We also examined problems women reported in accessing medical advice and treatment; because children in Pakistan must be taken to a health facility to receive most vaccinations, this can serve as a proxy for access to immunization services. Immunization coverage was negatively associated with problems getting money for treatment in Punjab, Sindh and KPK; with distance to the facility, transportation problems and not wanting to go alone in Punjab and Sindh; and with problems getting permission to go for treatment in Sindh and KPK. Coverage did not vary significantly with women's participation in major household decisions in any of the provinces.

After controlling for all other variables in the multivariable model, receiving TT injections was a significant predictor of complete immunization and the most important factor in every province (OR ranges from 1.70 in Sindh to 4.29 in Balochistan) (Table 3). Other factors varied between provinces. Urban residence was a strong and significant predictor in Balochistan (OR $=3.53)$. Wealth was significant in Sindh and $\mathrm{KPK}(\mathrm{OR}=1.46$ and 1.44 , respectively) while mother's education was significant in Punjab and $\mathrm{KPK}(\mathrm{OR}=1.94$ and 1.54, respectively). Distance to the health facility was significant in Punjab $(\mathrm{OR}=2.40)$.

\section{Discussion}

The PDHS surveys reveal substantial provincial differences in all indicators of childhood immunization, with Punjab and KPK showing 


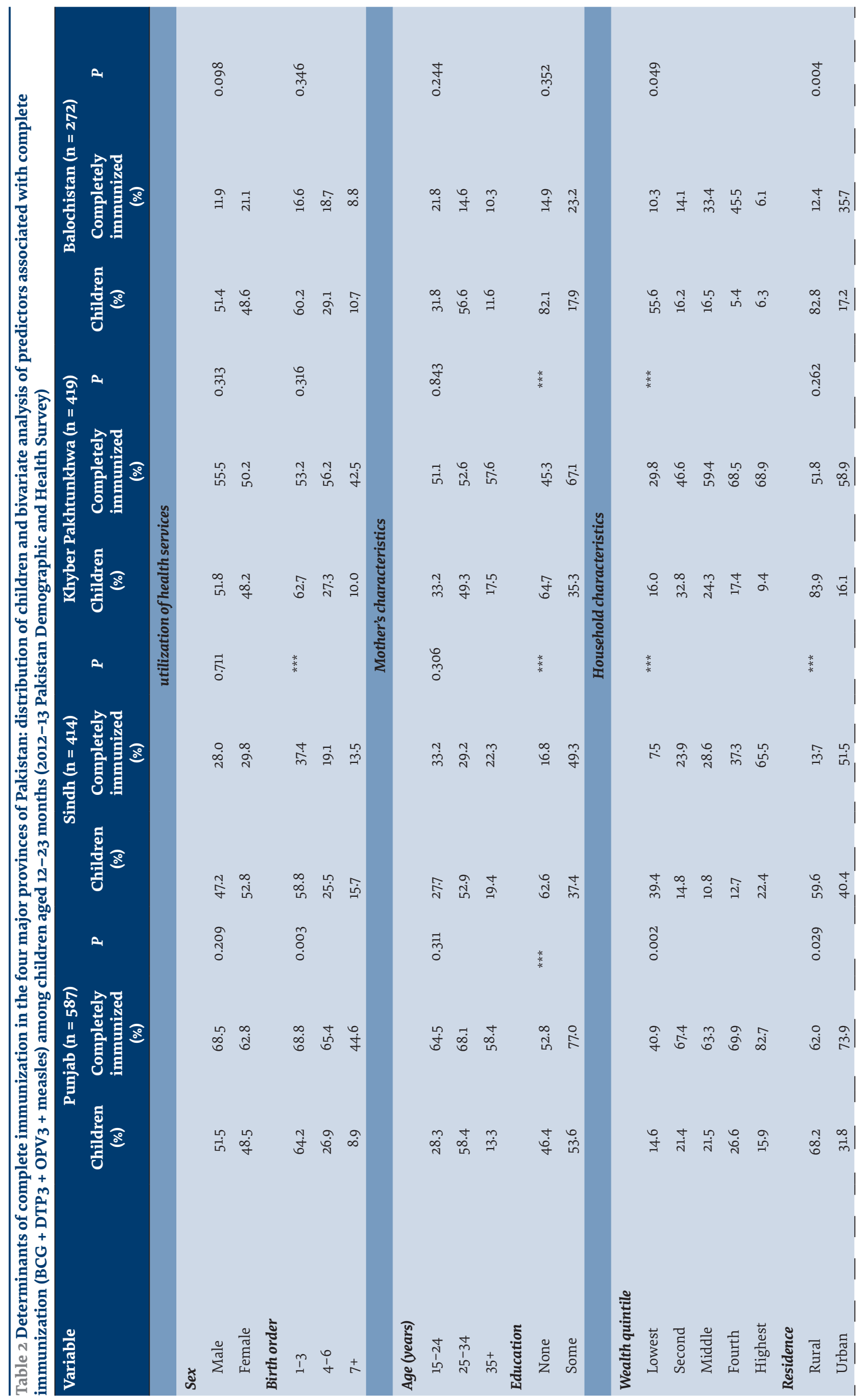









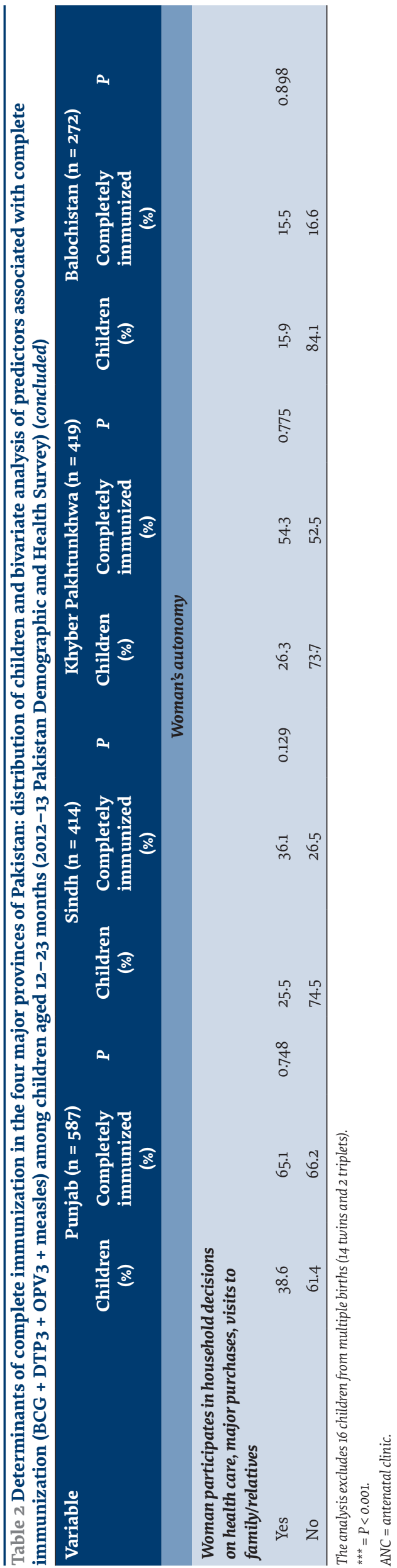

progress in recent years while the situation has deteriorated in Sindh and Balochistan. Notably, one predictor of complete immunization was significant in all 4 provinces in 2012-13: mothers' receiving at least 2 TT injections during pregnancy. This was also the strongest predictor in each province, confirming other studies in Pakistan which have found an association between mothers' utilization of health services during pregnancy and delivery and levels of childhood immunization $(13,19,21,22)$. Favin et al. have proposed a framework that categorizes the reasons for low childhood immunization into family factors and service-related factors (23). Receiving TT shots during pregnancy implies that a woman understands the value of immunization for disease prevention (positive family factors) and resides in a functional health service delivery environment (positive service-related factors). Thus, promoting TT injections may create an enabling environment for childhood vaccinations.

Other significant predictors of immunization varied between provinces as did levels and trends in immunization. This pattern is not unique to Pakistan. Analyses of national datasets in neighbouring India, which also suffers from low levels of immunization, have found significant differences in immunization coverage and predictors at the state and district levels which persist even when controlling for other factors $(24,25)$. These findings suggest that in countries where progress towards universal immunization is uneven, strategies to increase vaccine coverage can be more effective and efficient when designed at the subnational level. Thus, the devolution of the health system in Pakistan can be viewed as an opportunity to increase the impact of EPI because it permits interventions to be tailored to the local context. While district-level assessments and planning would be ideal $(5,14)$, the PDHS sample does not support analysis below the provincial level.

For EPI managers in Punjab and KPK, where over half the children are fully immunized, the goal is to build on positive trends: while EPI programmes in these provinces have been more successful in reaching poor, uneducated and rural residents, immunization coverage still lags for certain pockets of the population. Targeted interventions may be needed to reach high birth order $(7+)$ children, households in the lowest wealth quintile and children of mothers with no education. In Sindh and Balochistan, where coverage is extremely low for virtually all subgroups, EPI managers face greater challenges. Managers in these 2 provinces must work to normalize childhood immunization and reverse negative trends. In Sindh and KPK poverty is a key determinant of low immunization rates that managers must address.

Immunizations in Pakistan are free but mostly require traveling to a health facility. Especially in rural areas, Pakistani parents often blame difficulties in accessing services for not vaccinating children $(14,26)$. Assessments of Pakistan's EPI programme have concluded that weaknesses in service delivery, including the uneven distribution of EPI centres and staffing issues, limit access to immunization $(3,5)$. In addition, studies 


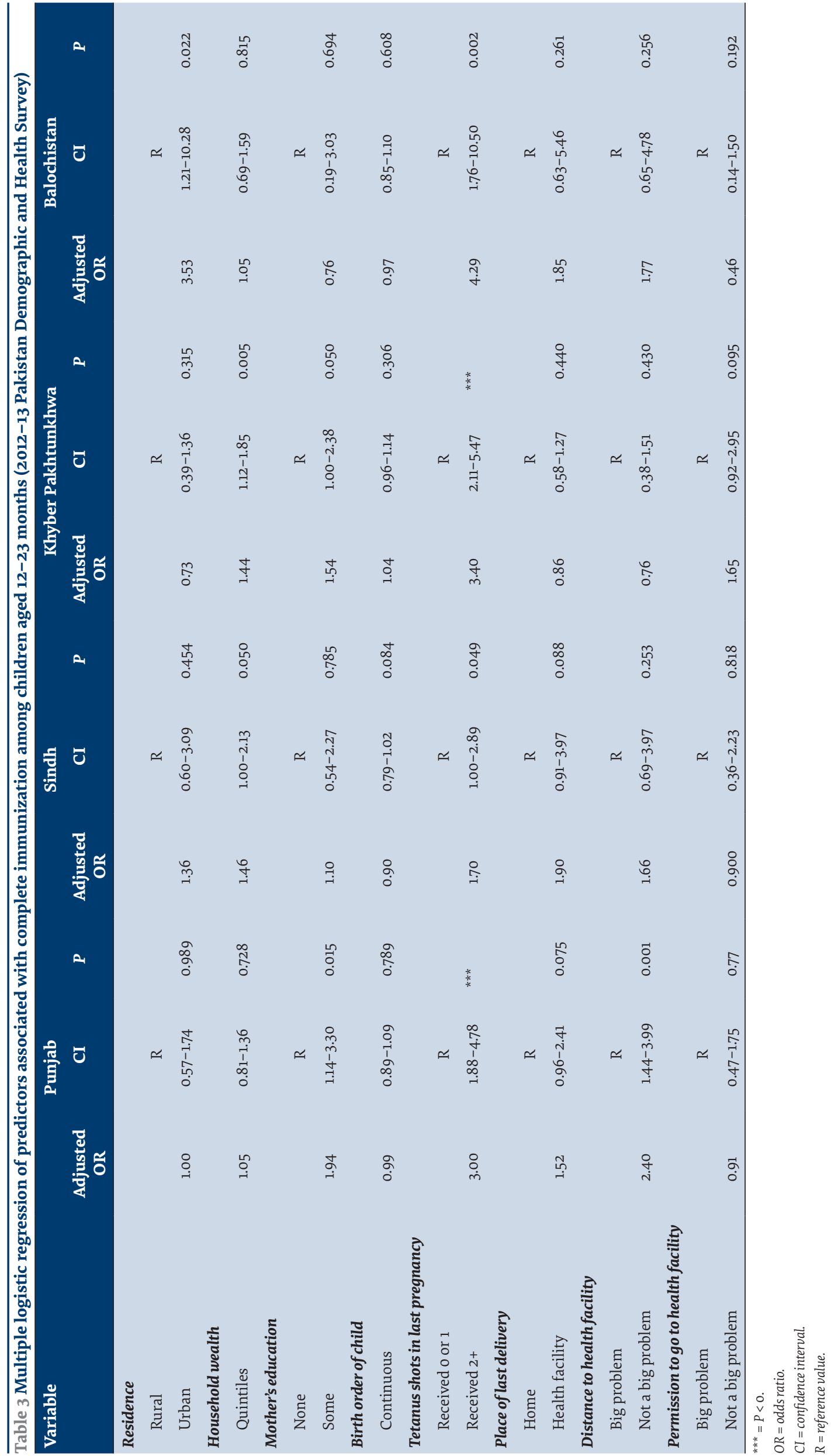


have found that living close to a facility is associated with higher vaccination rates in Pakistan $(14,26,27)$. The 2012-13 PDHS did not specifically ask about access to immunization services. According to the multivariable analysis, however, distance to the health facility was a significant determinant of immunization in Punjab, and urban residence was a significant determinant in Balochistan, which is the largest and least densely populated of the 4 provinces.

Our study had a number of strengths and limitations. By examining immunization data at the provincial level, this analysis is helping to fill a gap in the literature. This was possible because the PDHS was designed to produce reliable estimates of key indicators at the provincial level (19). Although different sources have yielded widely varying immunization estimates in Pakistan (3), the standardized methodology employed by the PDHS permits comparisons over time as well as between provinces. However, the analysis does have some limitations. Sample sizes at the provincial level for women with children aged 12-23 months are small, reducing the power of the analysis, and PDHS questionnaires did not collect information about many factors on both the supply and demand sides that have proven relevant in other research, such as the availability of immunization services and parental beliefs regarding immunization. Finally, most women (64-76\%) could not show vaccination cards for their children, so the data rely heavily on women's recall of vaccinations received up to 23 months previously. Weaknesses in household sources of information on immunization, including both vaccination cards and maternal recall, are well established. Depending on the setting, these kinds of data may overestimate coverage (e.g. if mothers feel positive responses to immunization questions are desirable) or they may underestimate coverage (e.g. if vaccination cards are not completely filled out or mothers do not remember all shots received) $(28,29)$. However, limiting this analysis to children with vaccination cards was not an option because it would have reduced the sample size below that needed for a provincial analysis; in addition, the minority of children with cards are unlikely to be representative of the broader population. While recall bias may have affected this analysis, it is not possible to determine in which direction.

\section{Conclusion}

Efforts to increase low rates of immunization are urgently needed across Pakistan. Some strategies are relevant nationwide, notably increasing access to and use of TT vaccination services during antenatal care. Yet this analysis demonstrates that viewing childhood immunization in Pakistan through a provincial lens can help achieve a deeper understanding of the challenges and potential strategies to boost coverage. Provincial EPI managers can use these insights to craft effective interventions that target locally relevant barriers to the supply of and demand for immunizations.

\section{Recommendations}

The findings suggest concrete steps that provincial EPI managers can take to increase immunization coverage. Encouraging maternal TT uptake has the potential to boost childhood immunization rates in every province, even among the poor and uneducated. Integrating immunization services with antenatal care - as part of a continuum of maternal, neonatal and child health care - can help increase TT coverage while also combatting community distrust of vaccinations (19). Other changes in service delivery are needed to increase access to immunization services, especially in Punjab and Sindh. While national immunization days and home outreach activities have boosted polio immunization rates in Pakistan, these special activities have disrupted and detracted from routine immunization (4). A more effective and sustainable solution is to expand the number of immunization centres in underserved areas to overcome challenges posed by distance and transportation (5).

There is also a need for increased health education and behaviour change communication. Previous studies have linked low immunization rates in Pakistan with a lack of knowledge, awareness and motivation among parents $(3,6,26)$. In this dataset, lower immunization coverage among women with no education and no regular exposure to mass media in Punjab, Sindh and KPK confirms that these may pose a problem. Health education interventions in Pakistan have a proven track record in increasing vaccination rates (30-32). In Punjab and KPK, EPI managers should direct health education to groups with low immunization rates, including parents who are poor, uneducated and have many children, using pictorial and other messages designed for low literacy audiences (31). In Sindh and Balochistan, broader media campaigns and health education interventions are needed to normalize childhood immunization and improve parents' knowledge. In these 2 provinces, where dropout rates are high and worsening, managers also should consider distributing a bigger, brighter immunization card that has proven more effective in reminding mothers about the next vaccination date (27).

The EPI managers in Sindh and KPK, where poverty is a key determinant of immunization, should consider offering economic incentives to increase demand for immunization. Programmes in Latin America and Asia have succeeded in increasing the utilization of preventive health services among the poor with conditional cash transfers $(33,34)$, and coupons for food and medicine doubled the completion rate for DPT3 among poor families in Karachi (35). In Pakistan, linking an existing state-sponsored cash transfer programme (the Benazir Income Support Programme) to childhood immunization has the potential to boost immunization rates; it is the country's largest social safety net, transferring cash to 4.7 million people, mainly women. 


\section{Acknowledgements}

The authors would like to thank Dr Sohail Agha and Dr Gayane Yenokyan for advising on the data analysis and Mr Mark Emerson for helping conduct the analysis. We are also grateful to Dr W Abdullah Brooks, Dr Wenfeng Gong, Dr Rozina Farhad Mistry, Dr Salim Wazir and Dr Thomas Wierzba for reviewing an earlier draft of the paper and sharing their insights.

Funding: None.

Competing interests: None declared.

\section{Différences provinciales en termes de niveaux, de tendances et de déterminants de la vaccination de l'enfant au Pakistan}

\section{Résumé}

Contexte: Des efforts visant à améliorer les taux de vaccination sont requis de toute urgence au Pakistan, mais les statistiques nationales masquent d'importantes différences locales en termes de niveaux et de déterminants de la vaccination.

Objectif : La présente étude avait pour objectif de déterminer dans quelle mesure les tendances et les niveaux récents de couverture vaccinale sont similaires ou différents dans les quatre provinces principales du Pakistan (le Pendjab, le Sindh, Khyber Pakhtunkhwa et le Baloutchistan), et quels sont les facteurs associés à une vaccination complète des enfants dans chaque province.

Méthode: Nous avons procédé à l'analyse des données issues des enquêtes démographiques et sanitaires du Pakistan 2006-2007 et 2012-2013. Les tendances de la couverture vaccinale parmi les enfants âgés de 12 à 23 mois ont été calculées dans chaque province. Des analyses bivariées et multivariées ont été conduites afin d'identifier les facteurs associés à une vaccination complète.

Résultats: La proportion d'enfants ayant bénéficié d'une vaccination complète avait significativement augmenté au Pendjab, mais avait au contraire connu une chute notable au Baloutchistan. La couverture complète était comprise entre $16,4 \%$ pour le Baloutchistan et 65,8 \% pour le Pendjab (2012-13). L'injection d'anatoxine tétanique pendant la grossesse était un facteur prédictif important de la vaccination complète dans toutes les provinces. Les autres facteurs prédictifs dans certaines provinces en particulier étaient : le fait d'habiter en ville pour le Baloutchistan, le niveau de richesse pour le Sindh et Khyber Pakhtunkhwa, le niveau d'éducation de la mère pour le Pendjab et Khyber Pakhtunkhwa, et la distance jusqu'à l'établissement pour le Pendjab.

Conclusions : Malgré la pertinence de certaines stratégies visant à augmenter la couverture vaccinale à l'échelle nationale, les responsables de programmes doivent rechercher des solutions spécifiques aux tendances et aux facteurs prédictifs des provinces. Cette analyse démontre que l'examen de la vaccination des enfants au Pakistan via un prisme provincial peut permettre d'obtenir une meilleure compréhension des problèmes et d'élaborer d'éventuelles stratégies pour augmenter la couverture.

$$
\begin{aligned}
& \text { الاختلافات في مستويات واتجاهات ومحددات تطعيم الأطفال بين الأقاليم في باكستان } \\
& \text { آدريانا كولز، ذو الفقار جورار، محمد شارجيل، فريد مدحت، راشيد نذير، ديليب كومار، أسلم فريد } \\
& \text { الخلاصة }
\end{aligned}
$$

الخلفية: ثمة حاجة ملحة لبذل جهود من أجل تحسين معدلات التطعيم في باكستان، ولئن كانت الإحصاءات الوطنية تخفي اختلافات محلية مهمة تتعلق بمستويات التطعيم ومحدداته.

الهدف: هدفنا من هذه الدر اسة تحديد مدى التشابه أو الاختلاف في الاتجاهات الحديثة ومستويات تغطية التطعيم في أربعة أقاليم رئيسية في باكستان

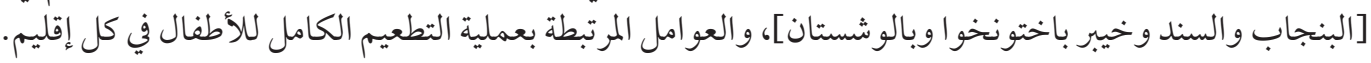

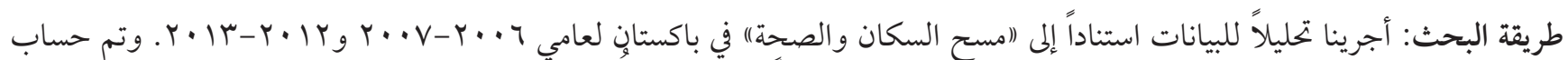

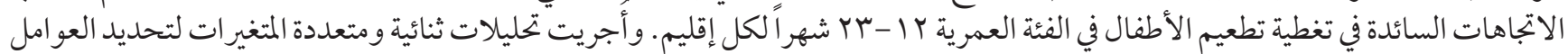
المرتبطة بالتطعيم الكامل.

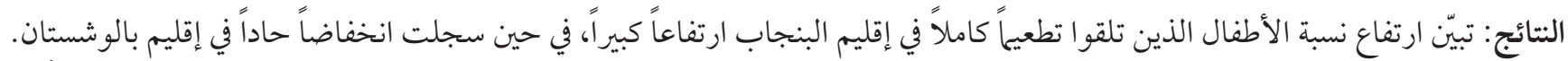

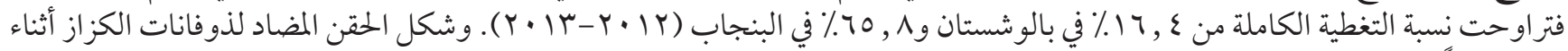



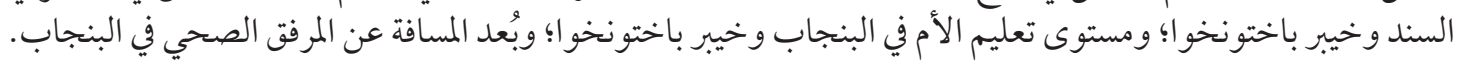




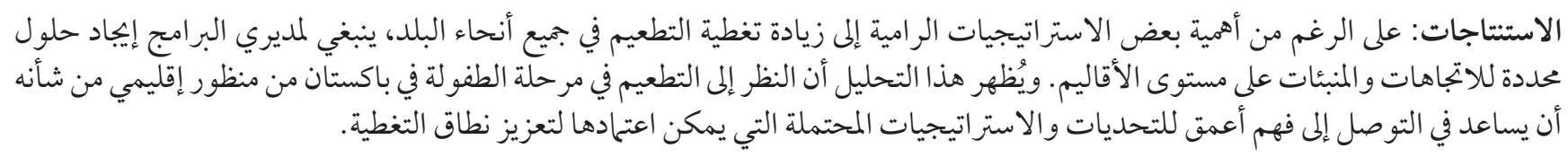

\section{References}

1. Khan T, Qazi J. Measles outbreaks in Pakistan: causes of the tragedy and future implications. Epidemiol Reports. 2014;2(1):1.

2. Farag NH, Wadood MZ, Safdar RM, Ahmed N, Hamdi S, Tangermann RH, et al. Progress toward poliomyelitis eradication - Pakistan, January 2014-September 2015. MMWR Morb Mortal Wkly Rep. 2015;64(45):1271-5. PMID:26584026

3. Hasan Q, Bosan AH, Bile KM. A review of EPI progress in Pakistan towards achieving coverage targets: present situation and the way forward. East Mediterr Health J. 2010;16(Suppl.):S31-8. PMID: 21495586

4. Mangrio NK, Alam MM, Shaikh BT. Is Expanded Programme on Immunization doing enough? Viewpoint of health workers and managers in Sindh, Pakistan. J Pak Med Assoc. 2008; 58(2):64-7. PMID:18333522

5. Masud T, Navaratne KV. The Expanded Programme on Immunization in Pakistan: Recommendations for improving performance. Washington, DC: World Bank; 2012.

6. Owais A, Khowaja AR, Ali SA, Zaidi AKM. Pakistan's expanded programme on immunization: an overview in the context of polio eradication and strategies for improving coverage. Vaccine. 2013; 31(33):3313-9. PMID:23707167

7. Khan MU, Ahmad A, Aqeel T, Salman S, Ibrahim Q, Idrees J, et al. Knowledge, attitudes and perceptions towards polio immunization among residents of two highly affected regions of Pakistan. BMC Public Health. 2015; 15:1100. PMID:26541976

8. Khowaja AR, Zaman U, Feroze A, Rizvi A, Zaidi AKM. Routine EPI coverage: subdistrict inequalities and reasons for immunization failure in a rural setting in Pakistan. Asia Pac J Public Health. 2015; 27(2):NP1050-9. PMID:22186395

9. Khowaja AR, Khan SA, Nizam N, Omer SB, Zaidi A. Parental perceptions surrounding polio and self-reported non-participation in polio supplementary immunization activities in Karachi, Pakistan: a mixed methods study. Bull World Health Organ. 2012; 90(11):822-30. PMID:23226894

10. Siddiqi N, Siddiqi A, Nisar N, Khan A. Mothers' knowledge about EPI and its relation with age-appropriate vaccination of infants in peri-urban Karachi. J Pak Med Assoc. 2010; 60(11):940-4. PMID:21375199

11. SteelFisher GK, Blendon RJ, Guirguis S, Brulé A, Lasala-Blanco N, Coleman M, et al. Threats to polio eradication in high-conflict areas in Pakistan and Nigeria: a polling study of caregivers of children younger than 5 years. Lancet Infect Dis. 2015; 15(10):118392. PMID:26179316

12. Hagan JE, Wassilak SGF, Craig AS, Tangermann RH, Diop OM, Burns CC, et al. Progress toward polio eradication - worldwide, 2014-2015. MMWR Morb Mortal Wkly Rep. 2015; 64(19):527-31. PMID:25996095

13. Bugvi AS, Rahat R, Zakar R, Zakar MZ, Fischer F, Nasrullah M, et al. Factors associated with non-utilization of child immunization in Pakistan: evidence from the Demographic and Health Survey 2006-07. BMC Public Health. 2014; 14:232. PMID:24602264

14. Cockcroft A, Andersson N, Omer K, Ansari NM, Khan A, Chaudhry UU, et al. One size does not fit all: local determinants of measles vaccination in four districts of Pakistan. BMC Int Health Hum Rights. 2009; 9 Suppl 1:S4. PMID:19828062

15. Nishtar S, Boerma T, Amjad S, Alam AY, Khalid F, ul Haq I, et al. Pakistan's health system: performance and prospects after the 18th Constitutional Amendment. Lancet. 2013;381(9884):2193-206. PMID:23684254

16. Shaikh S, Naeem I, Nafees A, Zahidie A, Fatmi Z, Kazi A. Experience of devolution in district health system of Pakistan: perspectives regarding needed reforms. J Pak Med Assoc. 2012;62(1):28-32. PMID:22352097

17. Pakistan Demographic and Health Survey 2013-2014. Islamabad and Calverton, Maryland: National Institute of Population Studies and ICF International; 2013.

18. National Institute of Population Studies and Macro International Inc. Pakistan Demographic and Health Survey 2006-2007. Islamabad and Calverton, Maryland: National Institute of Population Studies and ICF International; 2008.

19. Zaidi SMA, Khowaja S, Kumar Dharma V, Khan AJ, Chandir S. Coverage, timeliness, and determinants of immunization completion in Pakistan: evidence from the Demographic and Health Survey (2006-07). Hum Vaccin Immunother. 2014;10(6):1712-20. PMID:24784118

20. Rainey JJ, Watkins M, Ryman TK, Sandhu P, Bo A, Banerjee K. Reasons related to non-vaccination and under-vaccination of children in low and middle income countries: findings from a systematic review of the published literature, 1999-2009. Vaccine. 2011;29(46):8215-21. PMID:21893149

21. Siddiqi N, Khan A, Nisar N, Siddiqi AE. Assessment of EPI (expanded programme of immunization) vaccine coverage in a peri-urban area. J Pak Med Assoc. 2007;57(8):391-5. PMID:17902521

22. Shaikh S, Taj TM, Kazi A, Ahmed J, Fatmi Z. Coverage and predictors of vaccination among children of 1-4 years of age in a rural sub-district of Sindh. J Coll Physicians Surg Pak. 2010;20(12):806-10. PMID:21205546

23. Favin M, Steinglass R, Fields R, Banerjee K, Sawhney M. Why children are not vaccinated: a review of the grey literature. Int Health. 2012;4(4):229-38. PMID:24029668 
24. Mathew JL. Inequity in childhood immunization in India: A systematic review. Indian Pediatr. 2012;49(3):203-23. PMID:22484740

25. Sissoko D, Trottier H, Malvy D, Johri M. The influence of compositional and contextual factors on non-receipt of basic vaccines among children of 12-23-month old in India: A multilevel analysis. PLoS One. 2014;9(9). PMID:25211356

26. Naeem M, Khan MZUI, Adil M, Abbas SH, Khan MU, Khan A, et al. Inequity in childhood immunization between urban and rural areas of Peshawar. J Ayub Med Coll Abbottabad. 2011;23(3):134-7. PMID:23272455

27. Usman HR, Rahbar MH, Kristensen S, Vermund SH, Kirby RS, Habib F, et al. Randomized controlled trial to improve childhood immunization adherence in rural Pakistan: redesigned immunization card and maternal education. Trop Med Int Health. 2011;16(3):334-42. PMID:21159080

28. Cutts FT, Izurieta HS, Rhoda DA. Measuring coverage in MNCH: design, implementation, and interpretation challenges associated with tracking vaccination coverage using household surveys. PLoS Med. 2013;10(5):e1001404. PMID:23667334

29. Miles M, Ryman TK, Dietz V, Zell E, Luman ET. Validity of vaccination cards and parental recall to estimate vaccination coverage: a systematic review of the literature. Vaccine. 2013;31(12):1560-8. PMID:23196207

30. Andersson N, Cockcroft A, Ansari NM, Omer K, Baloch M, Ho Foster A, et al. Evidence-based discussion increases childhood vaccination uptake: a randomised cluster controlled trial of knowledge translation in Pakistan. BMC Int Health Hum Rights. 2009; 9(Suppl. 1):S8. PMID:19828066

31. Owais A, Hanif B, Siddiqui AR, Agha A, Zaidi AK. Does improving maternal knowledge of vaccines impact infant immunization rates? A community-based randomized-controlled trial in Karachi, Pakistan. BMC Public Health. 2011;11:239. PMID:21496343

32. Shaikh S, Memon S, Ahmed I, Amna, Manzoor R, Shaikh S. Impact of an IEC (information, education and communication) intervention on key family practices of mothers related to child health in Jamshoro, Sindh. Pak J Med Sci. 2014;30(3):611-8. PMID:24948990

33. Bassani DG, Arora P, Wazny K, Gaffey MF, Lenters L, Bhutta ZA. Financial incentives and coverage of child health interventions: a systematic review and meta-analysis. BMC Public Health. 2013;13(Suppl. 3):S30. PMID:24564520

34. Ranganathan M, Lagarde M. Promoting healthy behaviours and improving health outcomes in low and middle income countries: a review of the impact of conditional cash transfer programmes. Prev Med. 2012;55(Suppl.):S95-105. PMID:22178043

35. Chandir S, Khan AJ, Hussain H, Usman HR, Khowaja S, Halsey NA, et al. Effect of food coupon incentives on timely completion of DTP immunization series in children from a low-income area in Karachi, Pakistan: a longitudinal intervention study. Vaccine. 2010;28(19):3473-8. PMID:20199756 